\title{
DESCONFORTOS VIVIDOS NO COTIDIANO DE FAMILIARES DE PESSOAS INTERNADAS NA UTI ${ }^{\mathrm{a}}$
}

\author{
Discomfort experienced at the daily life of relatives of people admitted at ICU \\ Incomodidades vividas en el cotidiano de los familiares de personas internadas en la \\ UVI
}

Kátia Santana Freitas ${ }^{1}$

Fernanda Carneiro Mussi ${ }^{2}$

Igor Gomes Menezes ${ }^{3}$

\section{RESUMO}

Trata-se de uma pesquisa qualitativa que objetivou conhecer os desconfortos vividos no cotidiano de familiares de pessoas internadas na unidade de terapia intensiva (UTI). Foi realizada na UTI geral de um hospital público, em Salvador-BA, no segundo semestre de 2009. Nove familiares de pessoas internadas foram entrevistados. Empregou-se a técnica de análise da Teoria Fundamentada em Dados. Os resultados mostraram que a interação das famílias com a ameaça à vida de um de seus membros na UTI produziu, como desconforto central, a descontinuidade da vida cotidiana, a qual foi caracterizada por quatro categorias: vivendo a angústia da possibilidade de perda, vivendo uma cisão na vida familiar, sofrendo mudanças na vida social e profissional, tendo dificuldade para cuidar de si. Tais desconfortos podem ser minimizados com abordagem multiprofissional sensível às demandas das famílias e apoio de sua rede social.

Palavras-chave: Família. Enfermagem familiar. Cuidados de conforto. Relações familiares.

\begin{abstract}
It is a qualitative research that aimed to get to know the discomforts experienced at the daily life of relatives of people admitted at the intensive care unit (ICU). It happened on a general ICU at a public hospital, in Salvador-BA, by the second half of 2009. Nine relatives of people admitted were interviewed. The technique used was the analysis from the Grounded Theory. The results showed that the interaction of the families with the reality of life threat from the relative admitted, had as main discomfort, the discontinuity in their daily life, which was characterized by four categories: Living the distress of a possible loss, difficulties to take care of themselves, facing a separation in the family, suffering with changes in their social and professional lives. These discomforts can be minimized by the healthcare team's effectiveness to the demands of the family and the support of its social network.
\end{abstract}

Keywords: Family. Family nursing. Comfort care. Family relations.

\section{Resumen}

Se trata de una investigación cualitativa que tuvo como objetivo conocer las incomodidades experimentados en el cotidiano de personas que poseen un familiar internado en una Unidad de Vigilancia Intensiva (UVI). El estudio se realizó en la UVI general de un hospital público en Salvador (BA). Nueve familiares de personas internadas fueron entrevistados. Se empleó la técnica de análisis de la Teoría Fundamentada en Datos. Los resultados revelaron que la interacción de las familias con la amenaza a la vida del familiar enfermo produjo, como incomodidad central, la discontinuidad de la vida cotidiana, lo cual se caracterizó en cuatro categorías: Experimentación de la angustia de la posibilidad de pérdida del familiar; Dificultad para cuidarse a sí mismo; Experimentación de una división en la vida familiar; Sufrimiento por los cambios en la vida social y laboral. Esas incomodidades pueden ser reducidas con el abordaje multiprofesional sensible a las demandas de las familias y el apoyo de su red social.

Palabras-clave: Familia. Enfermería de la familia. Cuidados de conforto. Relaciones familiares.

\footnotetext{
'Doutora pela Escola de Enfermagem da Universidade Federal da Bahia (EEUFBA). Professora do Departamento de Saúde da Universidade Estadual de Feira de Santana. Feira de Santana - BA. Brasil. E-mail: ksfenfpro@hotmail.com; ²Doutora em Enfermagem. Professora Associada I do Departamento de Enfermagem Médico-Cirúrgica e Administração em Enfermagem da EEUFBA. Salvador - BA. Brasil. E-mail: femussi@ufba.br; ${ }^{3}$ Doutor em Psicologia. Professor Adjunto da Escola de Psicologia da UFBA. Salvador - BA. Brasil. E-mail: igmenezes@yahoo.com.br;
} 


\section{INTRODUÇÃO}

A hospitalização de um membro da família na unidade de terapia intensiva (UTI) é, em geral, um evento abrupto, inesperado e assustador para os familiares e implica sofrimento, mudanças na vida cotidiana e enfrentamento de novos desafios ${ }^{1}$. A vivência desse processo pode se configurar em uma situação de desequilíbrio na medida em que provoca a alteração de papéis e responsabilidades, problemas de relacionamento familiar, surgimento de doenças entre seus membros, redução dos rendimentos financeiros em virtude de despesas então instaladas e respostas psicológicas e fisiológicas².

Considerando a família um grupo de indivíduos vinculados por uma ligação afetiva e por um sentimento de pertença a esse grupo ${ }^{3}$, a hospitalização de um de seus membros na UTI pode levar os familiares à vivência de desconfortos. Esses podem ser compreendidos como alterações, perturbações e dificuldades de natureza física, psíquica e social decorrentes da interação do familiar com a internação de um membro na UTI e que ameaçam a sua integridade como ser biopsicossocial, interferem na capacidade de relação com o mundo e de organização e enfrentamento da situação e no bem-estar ${ }^{4}$.

Os desconfortos vivenciados pelo familiar são o resultado, portanto, das suas interações consigo mesmo, com aqueles que o circundam e com as situações que enfrenta no processo de doença e cuidado de um membro na UTI ${ }^{5}$.

Estudos têm mostrado que, durante o evento da hospitalização, os familiares sofrem sintomas de ansiedade, depressão e estresse pós-traumático ${ }^{6}$. Dentre as alterações psíquicas, constatou-se, predominantemente, ansiedade e uma proporção importante de casos de depressão, sendo necessária intervenção profissional para o restabelecimento da saúde mental ${ }^{6}$. Quanto às alterações fisiológicas, tem-se destacado o comprometimento do sono e da alimentação ${ }^{7}$. Têm sido relatadas, também, mudanças de comportamento, como a incorporação do uso de cigarros, de bebidas alcoólicas e de medicamentos.

Entende-se que os desconfortos produzidos na interação de familiares com a hospitalização de um membro na UTI podem ser minimizados quando a família se torna sujeito da atenção à saúde, como preconizam as políticas e os discursos de humanização ${ }^{8}$. A promoção do conforto a familiares, considerada uma das metas das práticas de cuidado em saúde e em enfermagem, visa contribuir para a re-stauração e/ou manutenção da potência pessoal e ânimo, da capacidade de mobilização de mecanismos de enfrentamento e dos papéis usuais da família e, portanto, para a minimização do desconforto ${ }^{9}$.

Todavia, evidencia-se a carência de estudos que abordem a temática ou o conceito desconforto na perspectiva de familiares, no contexto da unidade de terapia intensiva, sob uma perspectiva multidimensional. Empregando-se primeiro as palavras-chave enfermagem, família, cuidados intensivos e desconforto, e depois nursing, family, intensive care e discomfort ou comfort nas bases de dados LILACS, MEDLINE e SciELO, sem estabelecer limite de tempo, identificou-se oitenta e dois trabalhos. No entanto, após a leitura dos resumos, identificouse que somente seis artigos abordavam as experiências das famílias de pessoas adultas internadas em UTI e nenhum deles utilizava o termo desconforto no título ou resumo. Assim, evidenciou-se uma lacuna na produção de estudos com foco no desconfor to na perspectiva de familiares que têm um de seus membros na UTI. A literatura é vasta quando se trata de necessidades, estressores, sentimentos e vivências de familiares em situação de doença aguda de seus membros ${ }^{1,2,7,10}$, no entanto pouco se conhece sobre os desconfortos definidos pelosfamiliares, no seu cotidiano, face a interação com a internação de um membro na UTI, o que reforça a importância deste estudo.

Tendo em vista a escassez de trabalhos que abordem a temática, a importância da promoção do conforto como meta das práticas de cuidar em enfermagem, a família que precisa ser vista como sujeito das práticas de saúde com um olhar integral e, ainda, a convicção de que as respostas positivas do indivíduo internado ao tratamento podem decorrer da afetividade estabelecida com a sua rede social, torna-se fundamental conhecer os desconfortos vividos no cotidiano de familiares de pessoas internadas na UTI.

Assim, conhecer como a interação com o adoecimento agudo de um membro da família determina desconfortos no cotidiano familiar pode contribuir para o avanço do conhecimento na área da familia, auxiliar os profissionais de saúde, especialmente $\mathrm{a}(0)$ s enfermeira(o)s, a direcionar as práticas de cuidado aos familiares visando prevenir um estado severo de desconforto e facilitar o enfrentamento da hospitalização, bem como orientar reflexões para o enfoque familiar no âmbito das políticas ou programas de saúde pública no Brasil.

Com base no exposto, firmou-se como objetivo do estudo: Conhecer os desconfortos vividos no cotidiano de familiares de pessoas internadas na UTI.

\section{MÉTODO}

Estudo exploratório, de natureza qualitativa, realizado na UTI Adulto, de um hospital geral de grande porte, público, de ensino, que atende pessoas exclusivamente oriundas do Sistema Único de Saúde, localizado em Salvador-BA.

A UTI dispunha de 10 leitos ativos. Não foi planejada com sala de espera para visitantes, a qual foi adaptada no corredor, para acomodação dos familiares antes da visita. A equipe de saúde era composta por enfermeiras, técnicos de enfermagem, médicos plantonistas e fisioterapeutas.

A pesquisa teve início após ser aprovada pela Comissão de Ética para Análise em Projetos de Pesquisa em julho de 2009, protocolo CEP n ${ }^{0}$ 022/2009. Todos os aspectos contidos na Resolução nº. 196/96 do Conselho Nacional de Saúde foram respeitados para a garantia de proteção aos seus participantes. 
Os participantes do estudo foram nove familiares de pessoas internadas na UTI que atenderam aos critérios de inclusão: ter idade igual ou superior a 18 anos; ter um familiar na UTI com mais de 24h de internação, em condição crítica de saúde e com possibilidades de recuperação; desejar expressar a sua experiência e seus sentimentos.

As entrevistas semiestruturadas ocorreram no período de agosto a outubro de 2009. A primeira parte do instrumento de coleta de dados continha questões fechadas sobre dados sociodemográficos e de relacionamento com o familiar hospitalizado, e a segunda restringiu-se à questão norteadora: Gostaria que você falasse sobre as situações de desconfor to que tem vivido no seu cotidiano após a internação de seu familiar na UTI.

A abordagem dos familiares ocorria antes ou após o horário de visitas. Após serem esclarecidos os objetivos da pesquisa, era feito o convite para a participação e agendado o momento para a entrevista. Essas ocorreram em local privativo na UTI, isto é, na sala vaga e disponibilizada pela coordenação de enfermagem e pelo serviço de psicologia. As entrevistas foram gravadas e, posteriormente, transcritas na íntegra.

Para análise das respostas à questão norteadora foram utilizados os procedimentos de análise da Teoria Fundamentada em Dados. Esse método explora a riqueza e a diversidade da experiência humana e contribui para o desenvolvimento de teorias da realidade empírica, sobretudo as relativas afenômenos espećíicos, denominadas teorias substantivas ${ }^{11}$.

Na Teoria Fundamentada nos Dados, os conceitos são unidades básicas de análise. Na fase inicial da análise operou-se a codificação aberta das entrevistas, à qual corresponde a primeira conceituação dos dados na forma de códigos. A denominação dos códigos buscou dar significado ao evento ou incidente identificado. Nessa fase da análise, as entrevistas foram examinadas minuciosamente, linha por linha, para extrair os primeiros códigos. Uma vez identificados os códigos, procedeu-se ao agrupamento daqueles que indicavam o surgimento de um mesmo fenômeno. Pelo processo de comparação, os códigos identificados foram agrupados por suas similaridades e diferenças formando as categorias. Com o avanço da análise, as categorias foram construídas, recodificadas, combinadas ou comparadas entre si. 0 processo reflexivo de comparação e organização das categorias, procurando formas de agrupá-las, é denominado codificação axial, a segunda fase da análise da Teoria Fundamentada nos Dados. A análise na codificação axial foi lançada, como na aberta, questionando e comparando os dados e buscando relações entre as categorias. Após a codificação axial, passou-se à terceira eúltima fase da análise, a codificação seletiva que consistiu na identificação da categoria central em torno da qual as demais categorias foram integradas, da determinação e validação de sua relação com as outras categorias e dessas entre $\mathrm{si}^{10}$.

Elaborou-se na análise diagramas que constituíram em representações gráficas ou imagens visuais do pensamento analítico que ajudam a identificar como as categorias e subcategorias estão relacionadas umas com as outras.

\section{RESULTADOS}

\section{Caracterização dos familiares entrevistados}

Os nove familiares entrevistados tinham idade média de 39 anos e eram predominantemente mulheres, católicos(as), com o $2^{\circ}$ grau completo e/ou incompleto. A maioria vivia com companheiro(a), em união consensual e casados(as). Predominaram familiares com atividade laboral, a maioria autônomos. As famílias recebiam renda mensal predominante de até 3 salários mínimos, seguidas daquelas que recebiam de 4 a 5 salários. Quanto ao parentesco com o ente hospitalizado, a maior parte possuía laços de consanguinidade e eram irmãos(as), mãe e tios ou sobrinhos. A maioria dos familiares não tinha experiência anterior com internação de um de seus membros na UTI, deslocava-se para o hospital pelo menos uma vez por dia e passava, em média, 3 horas por dia nesse ambiente. 0 tempo de internação da pessoa doente foi, em média, 11 dias.

Os desconfortos vividos no cotidiano da família na UTI

0 processo de análise minuciosa dos dados permitiu revelar a experiência de desconforto das famílias no seu cotidiano que foi marcadamente expressa pela categoria central: Sofrendo uma descontinuidade na vida cotidiana (Diagrama 1).

Diagrama 1. Sofrendo uma descontinuidade na vida cotidiana: desconforto de familiares relacionado à condição de ter um membro na UTI.

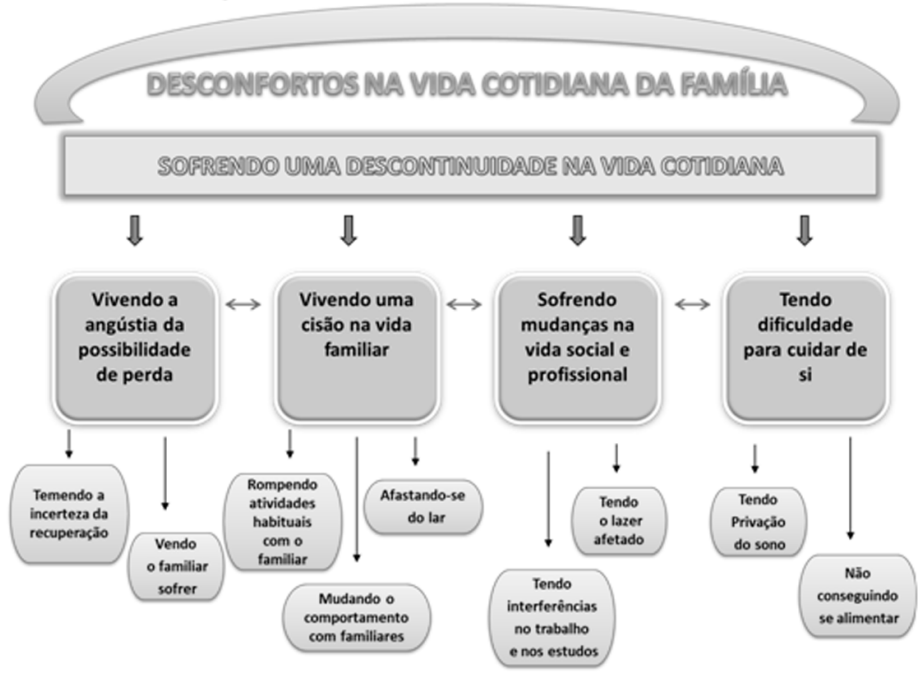


Para a família, o desconforto expressou-se pela impossibilidade da continuidade da vida pessoal e familiar como ocorria antes da entrada de um de seus membros na UTI. Quatro categorias representaram esse desconfor to e são descritas a seguir:

Vivendo a angústia da possibilidade de perda: expressou o desconfor to de familiares relacionado à incerteza de recuperação do seu membro na UTI e o medo de sua morte. Significou a interação constante com a inquietação, a aflição, o tormento do temor pelo que podia acontecer com esse membro e com a agonia de vê-lo sofrendo. Duas subcategorias revelaram esse desconforto:

Temendo pela incerteza da recuperação: significou a insegurança de familiares acerca das probabilidades de 0 membro da família restabelecer a saúde e retornar ao convívio familiar, como ilustram os depoimentos:

Pra gente que tá com um parente aí, fica todo mundo, a familia chocada, foi uma coisa inesperada, fica todo mundo na expectativa né, se vai reagir, se vai sobreviver...(Jasmin)

Eu não vou lhe dizer que é confortável você entrar numa UTI e ver um filho seu desse jeito, eu não vou Ihe dizer que é porque não é.... Porque dói, dói muito entendeu? Pra mim, só quando eu ver o meu filho em casa e ele falar benção mainha, tá tudo bem. (Girassol)

Vendo o familiar sofrer: significou para a família a interação constante com o sofrimento físico e psíquico do seu membro internado e com a preocupação decorrente dessa realidade.

O sofrimento que a gente vê ela passando ali, éo sofrimento... Toda cortada, cada dia que passa vai operando e vai abrindo de novo... De lá pra cá, ela já fez numa faixa de umas seis cirurgias no mesmo lugar, abrindo e reabrindo, quando falam que ela vai pra uma sala de cirurgia eu fico todo abatidão. (Cravo)

A noite é minha pior hora... Toda hora que eu acordava e sentava na cama meus filhos acordavam: - Mainha, mainha... Porque eu tô assim, tô bem, mas daqui a pouco dou uma crise de choro, aí eu choro... É difícil ver a situação dele, a pessoa que você ama, que sempre deu a vida por você, porque meu pai sempre foi tudo pra mim. (Violeta)

Vivendo uma cisão na vida familiar: significou a impossibilidade de continuidade da vida em grupo como ocorria antes da entrada do membro da família na UTI. A sua doença e internação geraram a interrupção no ritmo de vida e das interações sociais das famílias, como expressam as três subcategorias a seguir:

Rompendo abruptamente as atividades habituais com o familiar: a separação abrupta de um membro da família impossibilitou aos familiares desfrutarem do encontro com ele ao chegar em casa, de realizar atividades habituais conjuntas ( refeições, levar à escola, ir ao cinema, etc.). Enfim, a família passa a interagir com a cisão das interações antes estabelecidas no convívio cotidiano com o familiar na UTI.

A minha vida não tá como antes, a espera dele quando chega do trabalho, tomar banho, jantar, ir pro colégio, na hora que volta do colégio. (Girassol)

Quando eu chego em casa e não vejo o meu filho ... Ele é muito apegado a mim... (Azaleia)

Mudando o comportamento diante de outros familiares: a hospitalização do membro da família gerou acentuado desgaste emocional e físico e, com o passar do tempo, afetou as relaç̃̃es entre os demais membros devido à irritabilidade e falta de paciência, gerando momentos difíceis e modificando as relações entre seus constituintes.

Tenho que me controlar pra não ficar nervosa com a irmã dele, que éadolescente. Minha mãe também já é uma pessoa idosa, ela não entende, ela pergunta: - Robson tá comendo? Eu respondo: Ainda não...Ela tem 80 anos. Como é que ele tá ficando lá? Aí respondo: - Tá no soro. Aí, pra não me aborrecer, fico pouco lá em casa ....Mudou muita coisa. (Girassol)

Afastando-se do lar: significou a impossibilidade da continuidade da vida familiar em conjunto e da manutenção das atividades cotidianas. A doença provocou a descontinuidade do processo de viver em família, assim como a privou dos seus momentos em casa. Com a hospitalização de um de seus membros, havia a necessidade de estar próximo dele e, consequentemente, à distância de casa, da permanência de grande parte do tempo em um ambiente estranho e pouco acolhedor estruturalmente. Os familiares visitantes experimentaram a saudade de casa e do seu grupo familiar, principalmente os que eram provenientes de outros municípios.

A gente nunca tá bem fora de casa né... nunca pode viver do jeito que estava em casa. (Orquídea)

Eu não estou em minha casa, não estou com minha filha que só tem 8 anos, às vezes sinto falta dela. Meus filhos são grandes, mas precisam de mãe. (Lírio) 
Chegava de manhã de Alagoinhas e ficava de nove até onze horas lá na frente do hospital, não tinha acesso a nada, não podia entrar, nem sequer pegar um crachazinho pra ficar aqui dentro. Não podia ver ela, só onze horas, a visita acabou voltava lá pra frente. Cochilava, dormia até no banco lá fora até quatro horas. Dava quatro horas eu entrava, vinha ver ela de novo, conversava, conversava e pronto, pegava o relatório, saía cinco horas e ia pra casa.(Cravo)

Sofrendo mudanças na vida social e profissional: significou as mudanças no cotidiano dos membros da família para atender às demandas da internação do familiar na UTI, participação em exames e procedimentos médicos, conversas com a equipe do hospital, horários de visita, etc. Como a atenção dos familiares estava centrada no risco de vida de seu membro e em sua recuperação, precisavam ajustar a sua vida social e profissional para estar próximo a ele, acompanhando a sua evolução. Ocorreu uma interrupção imprevista no cotidiano, ainda que temporária, sendo afetado o mundo do trabalho, dos estudos e do lazer, como expressaram as duas subcategorias:

Tendo interferências no trabalho e nos estudos: os familiares necessitaram realizar ajustes na vida profissional, rever metas e/ou interromper atividades de estudo em razão das demandas da hospitalização, da preocupação com a evolução e a necessidade de estar próximo do membro hospitalizado. Assim sendo, alterações na frequência e qualidade das atividades foram experienciadas.

Eu chego cedo de Alagoinhas, porque posso não achar carro em outro horário. Além disso, tem que sair cedo pra pegar os dois horários da visita, também o custo está alto e tem o trabalho, tenho que dar alguma orientação aos funcionários da minha pequena loja. (Cravo)

Minha vida tá uma catástrofe, antes era só estudo, eu vinha estudando pro vestibular e tudo. $E$, agora, não é que eu vou desistir. Mas, agora? Ea pessoa do dia a dia pra conviver? Se ela tivesse doente, ah tá se tratando e tudo... Mas, na situação dela a gente não sabe o que pode acontecer. (Margarida)

A atenção dispensada ao membro internado consumiu dos familiares energia e tempo para o deslocamento ao hospital, especialmente quando residia em municípios distantes.

Tendo o lazer afetado: alguns familiares não conseguiam desfrutar de atividades prazerosas como antes faziam. Desta maneira, o lazer ou qualquer atividade que não estivessem relacionadas direta ou indiretamente ao cuidado ao seu membro internado não eram consideradas prioritários.

Eu não tô indo pra academia... não tem nem lógica ir pra academia com meu filho assim. (Girassol)

Tendo dificuldade para cuidar de si: essa categoria expressou a dificuldade da família em atender às suas necessidades humanas básicas, especialmente de sono, repouso e nutrição, implicando risco para a própria saúde. Os familiares não conseguiam se cuidar como antes, pois a preocupação com a condição do seu membro internado era enorme, fazendo com que relativizassem ou não se sentissem, muitas vezes, em condições de satisfazer as próprias carências. Duas subcategorias representaram esse desconforto:

Tendo privação de sono: significou para os familiares não conseguir manter o mesmo hábito de sono, ter o sono interrompido ou não conseguir dormir devido às preocupações e angústias provocadas pela internação, como a incerteza da recuperação do membro internado e as pequenas chances de interação com ele.

Com um parente aí...não tem como ter conforto, você vai pra casa fica pensando, ainda mais você que só vê uma hora, um familiar, vêm de manhã, outro (familiar) à tarde. Desconforto total, você não dorme direito, a preocupação é grande. (Jasmin)

Eu não consigo dormir, fico naquela preocupação ... eu não consigo dormir, fico preocupado demais, ontem eu preferi ficar aqui acompanhando tudo, lá fora aguardando, vendo a hora que ele entrou no centro cirúrgico, quando ele abriu o olho que ele me viu, me olhou..." (Azaleia)

A minha vida tá arrasada, enquanto minha filha não sair daí eu não fico boa, mudou tudo na vida, teve uma mudança horrível, eu não sei o que é dormir direito ... o que só tá me segurando mesmo é o Espirito Santo de Deus. (Tulipa)

Não conseguindo se alimentar: retratou a dificuldade dos familiares para comer ou a perda do apetite em razão do sofrimento e da possibilidade de perda do seu membro.

Minha vida parou um pouquinho ... Não, parou totalmente, porque quando a gente tem filhos não pode parar, né... Mas no momento que eu paro eu fico assim um pouco deprimida, não tô me alimentando direito, tenho fome, mas não desce, trava. (Violeta) 
Não consigo me alimentar, eu já perdi quase cinco quilos. Depois que ele tá aqui, eu me pesei e quase não acreditei. Entendeu? É um desconforto muito grande. (Azaleia)

Eu não sei o que é comer direito...(Tulipa)

\section{DISCUSSÃO}

Os desconfortos vividos pelos familiares no cotidiano, em razão do membro da família na UTI, evidenciaram os efeitos de sua interação com a situação de doença aguda de um de seus membros. 0 cotidiano da família transformou-se, e ela sofreu uma descontinuidade da vida cotidiana expressada pelos desconfor tos da angústia da possibilidade da perda do familiar, da cisão na vida familiar, das mudanças na vida social e profissional e das dificuldades para cuidar de si.

0 familiar, ao vivenciar a angústia da possibilidade de perda, devido à incerteza de recuperação do seu membro e ao sofrimento do mesmo, experimenta a antecipação da perda, que é extremamente perturbadora e dolorosa. 0 desconforto da família significa medo, e sempre o maior de todos, o medo da morte ${ }^{10}$. 0 desconforto é presenciar o seu familiar sofrendo, dependendo de equipamentos e dos profissionais do hospital, um sofrimento que também passa a ser seu. Esses desconfortos não podem ser eliminados em razão da condição de risco de vida do familiar doente, contudo podem ser minimizados sobretudo quando os familiares sentem-se acolhidos e assegurados da qualidade técnica e científica do atendimento, ao receberem informações realísticas e claras, mas permeadas, sempre que possivel, de mensagens de confiança e solidariedade e ao sentirem-se seguros percebendo que as práticas de cuidar são sempre conduzidas no sentido de preservar a qualidade e a dignidade da vida do seu membro.

0 primeiro impacto da hospitalização na vida familiar foi a separação física de um de seus membros, já que interrompeu a vida em conjunto, impedindo a continuidade das suas atividades habituais. A literatura acerca das vivências dos familiares apontou também para o surgimento de uma lacuna a ser preenchida na família, ocasionada pela falta do seu membro no dia-a-dia ${ }^{13}$. Essa ausência no meio familiar por si só já significa uma perda, antecipa a probabilidade da cisão definitiva, coloca a família diante do desconhecido, da incerteza e da vulnerabilidade. Tal desconforto é potencializado, especialmente, quando a relação de proximidade e convívio é estreita, de dependência e cuidado. A separação pode interferir no cuidado familial, que são as ações de cuidado realizadas dentro da família uns com os outros, que objetiva o seu desenvolvimento, bem-estar, realização pessoal, inserção e contribuição social ${ }^{14}$ especialmente quando o familiar ausenta-se do lar para acompanhar as demandas da hospitalização do membro internado.
A redução do convívio no domićlio com os demais membros da família também representou um desconforto, especialmente quando os pais precisavam distanciar-se dos filhos para estarem mais próximos do membro hospitalizado, não conseguiam relaxar longe dos filhos que ficaram em casa sob o cuidado de outras pessoas. A rotina hospitalar passa a incorporar a vida da família, que vivencia, em graus diferenciados, uma desarticulação do dia-a-dia, deixando em segundo plano as preocupações cotidianas. A família experimenta desconfortos devido à distância de casa, vive o conflito entre a necessidade de estar em casa e no hospital, o que gera tensão emocional e afeta o grupo familiar ${ }^{15,16}$.

A mudança de comportamento perante os outros foi um desconfor to que expressou a cisão da vida familiar. Estudos também constataram que familiares manifestaram sentimentos de estresse na interação com os demais membros, pela necessidade de estar próximo do familiar hospitalizado e percepção do aumento da responsabilidade e da necessidade de tomada de decisões difíceis, como as relacionadas à situação do membro na UTT ${ }^{7,10}$. Ocorrem mudanças de comportamento entre os familiares irmãos e entre cônjuges, uma vez que 0 estresse da doença provoca muitos conflitos, o que interfere no equilíbrio e na estrutura emocional dos integrantes da família, levando a distúrbios de conduta e, consequentemente, modificando as relações ${ }^{17}$.

0 momento vivido pela família foi também caracterizado pelas mudanças na vida social e profissional que significaram o desconforto associado ao comprometimento em quantidade e qualidade das atividades relacionadas ao trabalho, estudos e lazer dos familiares. 0 trabalho e os estudos precisaram de um rearranjo que viabilizasse a participação do familiar na rotina hospitalar. Os familiares desligaram-se um pouco das suas atividades laborais devido à atenção que precisaram dispensar a seu membro na UTI. Sentiram-se muitas vezes sem a disposição necessária para participar do mundo do trabalho e dar continuidade as suas atividades de formação profissional, não deram conta ou relativizaram a importância de certas atividades ao interagir com o risco de vida do familiar hospitalizado. Tais mudanças geraram ansiedade e preocupação com o desempenho prejudicado. Assim, a doença grave de um de seus membros pode desarticular a vida profissional e financeira da família. Horn ${ }^{7}$ também identificou a necessidade de familiares saírem ou reduzirem o trabalho para estar próximos ao familiar internado. Constatou também que a preocupação com o emprego e com as finanças provocaram estresse e preocupação para a família.

0 prejuízo na vida social, expresso pelo desconforto de ter o lazer afetado, foi presente na vida das famílias estudadas, que se defrontaram não só com dificuldades para manter atividades habituais de lazer, mas também sentiram a falta de prazer ou disposição para se entreterem, individualmente ou em grupo, e outros minimizaram a importância desses momentos face a tantos desconfortos 
experienciados. Beuter e colaboradores ${ }^{10}$ verificaram que os familiares diminuíram as atividades de lazer, como assistir televisão, jogar e realizar caminhadas, o convivio em família e a inserção no trabalho, pois dispendiam mais tempo deslocandose de casa para o hospital e realizando contatos telefônicos e menos tempo com as crianças e o restante da família em casa e no trabalho.

A atenção voltada, essencialmente, para o membro em risco de vida resultou, também, em desorganização da vida pessoal dos familiares, que culminou na dificuldade para cuidarem de si mesmos, de atender suas necessidades pessoais. Tal processo gerou privação do sono, dificuldade para se alimentar com as mesmas qualidade e frequência anteriores à internação. A manifestação dessas alterações refletiu um estado de desequilibrio nos familiares, já que as necessidades humanas básicas em estados de equilibrio são latentes. Outros pesquisadores ${ }^{7}$ também identificaram que familiares não se alimentavam adequadamente e não conseguiam descansar em função da demanda de cuidado relacionadas ao membro hospitalizado e das preocupações com a casa. Constataram piora na qualidade e na quantidade do sono, principalmente naqueles que dormiam na sala de espera da UTI, diminuição do apetite, redução da frequência da ingesta e incorporação de alimentos pobres em nutrientes a dieta, ficando expostos a risco de infecções e problemas gástricos ${ }^{7,16}$. Depreende-se que os familiares precisam ser encorajados pelos profissionais de saúde a tentar manter os padrões usuais de atividade durante o dia na tentativa de obterem melhor padrão de sono à noite, estimulados a distrações com leituras, músicas e caminhadas, até mesmo para ida ao hospital. Além disso, é preciso que as instituições hospitalares ofereçam aos familiares uma estrutura ambiental confortável, incluindo salas de espera com mobiliário cômodo, disponibilidade de local para lanche e refeições, acesso a água, entre outros.

Os desconfortos identificados revelaram a família em condição de vulnerabilidade. Expressaram impotência, incertezas, temores, ameaças reais ou imaginárias, mudanças de comportamento, alteração de hábitos de vida, perdas, entre outros, interferindo na integridade dos familiares como ser biopsicossocial, na capacidade de relação com o mundo e de organização e enfrentamento da situação, e prejudicando o seu bem-estar.

A partir dos resultados deste estudo, entende-se que práticas de cuidar devem ser realizadas pelos trabalhadores em enfermagem para promover conforto às famílias. Uma escuta sensível acerca dos sentimentos e necessidades dos familiares, o oferecimento de informações claras e o incentivo para expressarem sentimentos, dúvidas e dificuldades no enfrentamento da experiência e para refletir sobre a própria situação podem contribuir para minimizar o desconforto da descontinuidade da vida cotidiana. 0 reconhecimento das forças da família for talece a autoestima e melhora a capacidade de lidar com as demandas da doença.
Torna-se necessário incentivar o apoio entre familiares e a busca de fontes de apoio social, quando necessário e desejado.

Os profissionais de saúde junto com os trabalhadores em enfermagem devem focalizar o acolhimento no cuidado às famílias, favorecer sempre a proximidade do familiar junto ao ente, reconhecer, diante dos familiares, as alterações e pertubações que enfrentam e os ameaçam e ajudá-los a encontrar no âmbito de suas possibilidades maneiras de melhor cuidaram de si mesmos e de organizarem a vida pessoal e familiar.

Dentre as políticas de saúde adotadas pelo Ministério da Saúde, o programa Visita Aberta e Direito ao Acompanhante 8 tem reforçado o reconhecimento da família como sujeito do cuidado em saúde e em enfermagem. Defende, como estratégias para a inclusão das famílias e promoção do conforto, espaços de conversa entre profissionais e famílias para se obter relações solidárias e atitudes de cooperação, assim como a ampliação do horário de visita ${ }^{7}$. Portanto, o cuidado aos familiares deve ser entendido como um direito da família e um desafio a ser alcançado nos serviços de saúde brasileira.

Para que se possa atender às Políticas de humanização instituídas pelo Ministério da Saúde ${ }^{8}$, as quais sinalizam a importância do atendimento humanizado tanto aos usuários como a seus familiares, é necessário uma atuação integrada dos profissionais de saúde. A enfermagem tem descoberto, no cuidado com as famílias, que sua atuação não pode ser solitária, mas articulada com outros profissionais, em uma abordagem interdisciplinar. A complexidade que abarca a experiência da família, especialmente face à hospitalização, requer a integração de saberes e práticas de outras disciplinas visando à atenção integral à família ${ }^{18}$.

Se os desconfortos da vida cotidiana nem sempre poderão ser minimizados pela ajuda dos profissionais de saúde, é importante destacar que a aceitação dos familiares nos espaços de cuidado, como sujeitos dignos de cuidado, 0 acolhimento, 0 oferecimento da informação desejada, o suporte emocional, a garantia da segurança no atendimento do membro hospitalizado, a comodidade no ambiente hospitalar, as relações de confiança e respeito podem minimizar os desconfor tos da família na interação com os objetos institucionais, diminuindo a sobrecarga do sofrimento por ela vivenciada.

\section{CONSIDERAÇÕES FINAIS}

0 estudo revelou que o desconforto central experienciado no cotidiano de familiares de pessoas internadas na UTI foi a descontinuidade da vida cotidiana, pois a família vive a angústia da possibilidade de perda de seu membro, uma cisão na vida familiar, a dificuldade para cuidar de si e mudanças na vida social e profissional. A investigação aponta que esses desconfortos podem ser minimizados pela rede de suporte social e espiritual da família e por práticas de cuidar dos trabalhadores em enfermagem integrados aos demais profissionais de saúde, os quais precisam oferecer acolhimento, 
informação, suporte emocional, segurança e comodidade no ambiente hospitalar.

0 presente estudou ampliou o conhecimento disponível sobre o cotidiano das famílias que enfrentam a internação de um de seus membros na UTI, especialmente dos desconfortos vividos por ela, e pode contribuir para orientar o ensino e a pesquisa e as práticas de cuidar de profissionais de saúde, bem como para o desenvolvimento de modelos teóricos representativos da experiência de desconforto de familiares.

Apesar das contribuições trazidas pela pesquisa, ressalta-se como limite a sua realização em um contexto restrito a uma UTI pública de um hospital situado no município de Salvador, Bahia. Tal fato reforça a necessidade de replicação do estudo em outros contextos institucionais públicos e privados e em regiões diferentes para que se possa expandir o conhecimento sobre as especificidades dos desconfortos vividos pelos familiares, bem como identificar como os familiares podem ser ajudados a enfrentar essa dolorosa experiência. A escassez de estudos sobre o fenômeno desconforto na perspectiva de familiares limitou também a comparação dos achados desta pesquisa. Todavia, constatou-se que investigações que exploraram sentimentos e necessidades de familiares revelaram alterações e perturbações que mantiveram relação com 0 desconforto referido pelos familiares participantes desse estudo.

0 emprego da técnica de analise da Teoria Fundamentada em Dados foi fundamental para a construção desse saber, ajudando a explorar a riqueza e a especificidade da experiência de desconforto da família que tem um de seus membros na UTI.

\section{REFERÊNCIAS}

1.Silveira AO, Angelo M. Interaction experience for families who lives with their child's disease and hospitalization. Rev Latino-Am Enfermagem. 2006; 14(6): 893-900.

2.Costa JB, Felicetti CR, Costa CRLM, Miglioranza DC, Osaku EF, Versa GLGS, et al. Fatores estressantes para familiares de pacientes criticamente enfermos de uma unidade de terapia intensiva. J Bras Psiquiatr. 2010; 59(3): 182-89.

3.Galera SAF, Luis MAV. Principais conceitos da abordagem sistêmica em cuidados de enfermagem ao indivíduo e sua família. Rev Esc Enferm USP. 2002; 36(2): 141- 47.

4.Gameiro MH. Sofrimento na doença. In: Análise conceptual efenomenológica do sofrimento humano. Coimbra: Quarteto; 2003. p. 29-44.

5. Mussi FC, Koizumi MS, Angelo M, Lima MS. Perda da espontaneidade da ação: o desconforto de homens que sofreram infarto agudo do miocárdio. Rev Esc Enferm USP. 2002 jun; 36(2): 115-24.

6.Pochard F, Darmon M, Fassier T, Bollaert PE, Cheval C, Coloigner M, et al. Symptoms of anxiety and depression in family members of intensive care units patients before discharge or death. A prospective multicenter. J Crit Care. 2005; 20(1): 90-6.
7. Horn EV, Tesh A. The effect of critical care hospitalization on family members: stress and responses. Dimens Crit Care Nurs. 2000; 19(4): 40-9.

8.Ministério da Saúde (BR). Secretaria de Atenção à Saúde. Núcleo Técnico da Política Nacional de Humanização. Humaniza SUS: visita aberta e direito a acompanhante. $2^{\mathrm{a}}$ ed. Brasília; 2007.

9. Carraro TE, Knobel R, Frello AT, Gregório VRP, Grüdtne DI, Radünz $V$, et al. 0 papel da equipe de saúde no cuidado e confor to no trabalho de parto e parto: opinião de puérperas. Texto \& Contexto Enferm. 2008; 17(3): 502-09.

10.Beuter M, Brondani CM, Szareski C, Cordeiro FR, Roso CC. Sentimentos dos familiares acompanhantes. Esc Anna Nery. 2012 jan-mar; 16 (1): 13440.

11.Strauss A, Corbin J. Pesquisa qualitativa: técnicas e procedimentos para o desenvolvimento de teoria fundamentada. Porto Alegre: Artmed; 2008

12.Almeida AS, Aragão NRO, Moura E, Lima GC, Hora EC, Silva LASM. Sentimentos dos familiares em relação ao paciente internado na unidade de terapia intensiva. Rev Bras Enferm. 2009; 62(6): 844-49.

13.Urizzi F, Corrêa AK. Relatives' experience of intensive care: the other side of hospitalization. Rev Latino-Am Enfermagem. 2007; 15(4): 598-604.

14.Elsen I. Cuidado familial: uma proposta inicial de sistematização conceitual. In: Elsen I, Marcon SS, Silva MRS. 0 viver em família e sua interface com a saúde e a doença. Maringá: Eduem; 2004. p.19-28.

15.Nunes MDR, Dupas G, Ferreira NMLA. Diabetes na infância / adolescência: conhecendo a dinâmica familiar. Rev Eletr Enferm. [on- line]. 2007 [citado 2010 jun 10]; 9(1): [aprox.11 telas]. Disponível em: http://www.fen.ufg.br/ revista/v9/n1/v9n1a09.htm.

16.Souza AlJ. Cuidando de famílias: identificando ações de cuidado e não cuidado nos familiares. In: Elsen I, Marcon SS, Silva MRS. 0 viver em família e sua interface com a saúde e a doença. Maringá: Eduem; 2004. p.313-25.

17.Montefusco SAR, Bachion MM. Manutenção do lar prejudicada: diagnóstico de enfermagem em familiares de pacientes hospitalizados com doenças crônicas. Rev Eletr Enferm. [on-line]. 2011 [citado 2012 jun 21]; 13(2): [aprox.7 telas]. Disponível em: http://www.fen.ufg.br/revista/v13/n2/ v13n2a04.htm

18. Benito GAV, Silva LL, Meirelles SBA. Interdisciplinaridade no cuidado as famílias: repensando a prática em saúde. Fam Saude Desenv. 2003; 5(1): 66-72.

\section{NOTA}

${ }^{\mathrm{a}}$ Trabalho integrante de projeto financiado pelo CNPq - Edital Universal 